\title{
The Rhodium-Catalyzed Asymmetric 1,4-Addition
}

$$
\prod_{\mathrm{O}}^{\mathrm{R}^{1}=\mathrm{R}^{2}-\mathrm{B}(\mathrm{OH})_{2}} \mathrm{R}_{(1.4-5.0 \text { equiv })}
$$

$R^{1}, R^{2}=$ various (cyclic) substituents

$\mathrm{R}^{3}=$ various alkenyl, aryl moieties

Selected examples:

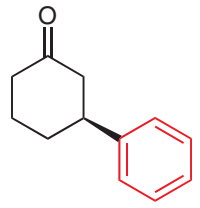

$>99 \%$ yield $97 \%$ ee

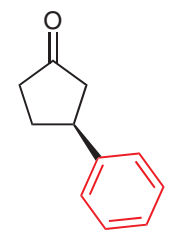

$93 \%$ yield $97 \%$ ee

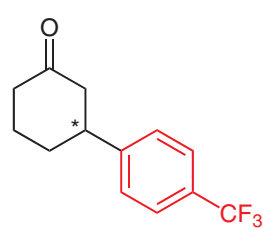

$70 \%$ yield $99 \%$ ee

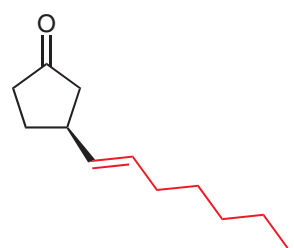

$93 \%$ yield $97 \%$ ee

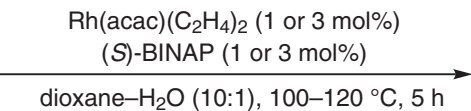

dioxane- $\mathrm{H}_{2} \mathrm{O}(10: 1), 100-120^{\circ} \mathrm{C}, 5 \mathrm{~h}$<smiles>[R]C(=O)CC([R])[R]</smiles>

up to $99 \%$ yield up $99 \%$ ee

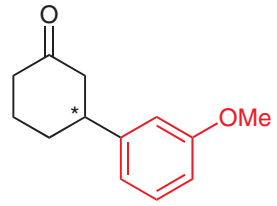

$97 \%$ yield $96 \%$ ee

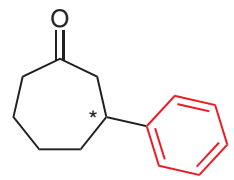

$51 \%$ yield $93 \%$ ee

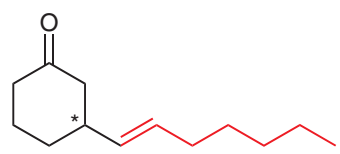

$98 \%$ yield $94 \%$ ee

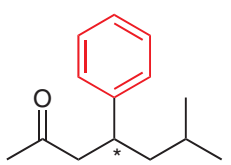

$82 \%$ yield
Significance: In 1998, Hayashi and Miyaura reported the first asymmetric 1,4-addition of aryl- or alkenylboronic acids to various $\alpha, \beta$-unsaturated ketones. A combination of a rhodium(I) catalyst with ethylene ligands, (S)-BINAP as chiral ligand and high reaction temperatures provided the corresponding addition products in remarkably high yields and enantiomeric ratios.
Comment: This method provides numerous synthetic advantages, such as a high functional group tolerance of the organoboron reagent and aqueous reaction conditions, leading to products in very high enantiomeric ratios, which makes it the method of choice for the synthesis of these scaffolds. Thus, the scope for the reaction was further developed by using other Michael systems, such as $\alpha, \beta$-unsaturated amides, phosphonates, and nitroalkenes (see Review below).

Review: T. Hayashi, K. Yamasaki Chem. Rev. 2003, 103, 2829-2844.

\section{Key words}

rhodium catalysis

asymmetric catalysis

boronic acids 